\title{
Erythropoietic Protoporphyria Masquerading as Angioedema in a 4-Year-Old Female
}

\author{
Helen C. Wang, MD; Ejaz Yousef, MD
}

\begin{abstract}
Angioedema is a common presentation with a broad differential, including rare disorders with which an allergist must be familiar. Our objective was to report a case of swelling of the hands and feet mimicking angioedema with hepatomegaly in a 4-year-old girl. The patient was evaluated for painful swelling of the hands and feet after exposure to sun. Examination revealed edema and erythema of the extremities and hepatomegaly. Laboratory evaluation included elevated liver transaminases and plasma protoporphyrin, with normal urine porphyrins. Liver biopsy confirmed the diagnosis of erythropoietic protoporphyria, a disorder of heme biosynthesis in which patients may present with photosensitivity and angioedema. It is important for allergists to recognize this entity in patients with cutaneous disorders of unclear etiology in order to prevent possible life-threatening sequelae.
\end{abstract}

Angioedema is a common presenting symptom among allergy practices. Angioedema is caused by increased vascular permeability in the subcutaneous tissue of the skin and respiratory and gastrointestinal tracts. ${ }^{1}$ Acute angioedema is most often due to an immunoglobulin E ( $\mathrm{IgE}$ )-mediated response to an inciting allergen and is classified as a type I hypersensitivity reaction. ${ }^{1}$ However, there is a broad differential for angioedema, including hereditary and acquired disorders. One rare diagnosis that occurs in the pediatric population and that allergists must be familiar with is angioedema-like cutaneous findings due to pho-

H.C. Wang, E. Yousef-Division of Allergy and Immunology, Alfred I. duPont Hospital for Children, Nemours Children's Clinic, Wilmington, Delaware; Thomas Jefferson University, Philadelphia, Pennsylvania Correspondence to: Dr. Ejaz Yousef, Division of Allergy and Immunology, Alfred I. duPont Hospital for Children, 1600 Rockland Road, Wilmington, DE; E-mail: eyousef@nemours.org

DOI 10.2310/7480.2006.00003 tosensitivity caused by cutaneous porphyrias. ${ }^{2} \mathrm{We}$ present a case report of a child with a swelling of hands and feet that mimicked angioedema and hepatomegaly, ultimately diagnosed as erythropoietic protoporphyria (EPP).

\section{Case Presentation}

A 4-year-old previously healthy African American girl presented to the emergency department with swelling of hands and feet. The patient had been at the beach all day, playing in the water and sand. After a few hours, she had begun to experience a burning sensation in her hands and feet, with associated swelling and redness of the skin. No hives, blistering, swelling of lips or face, or respiratory or gastrointestinal symptoms were noted. There was no history of any insect bites or trauma. There was no medication or unusual food ingestion before this episode. The patient's medical history included two episodes of a similar nature at the age of 2 years, which were noted to be associated with spending the day at the beach. These episodes resolved spontaneously after 2 days. The patient 
also had a history of hives with amoxicillin use as an infant; otherwise, there was no history of recurrent urticaria. Family history was significant for allergic rhinitis in the mother, asthma in her halfbrother, and atopic dermatitis in her half-sister. There was no reported family history of recurrent swelling of the skin, chronic hives, or childhood or unexplained deaths.

Examination revealed a well-nourished welldeveloped female in no apparent distress. Vital signs were stable, without fever, tachypnea, or tachycardia. Weight and height were both in the 25th percentile for her age. Of note, an examination of her extremities revealed erythema, edema, and tenderness on palpation of the hands and feet. Her skin was hyperkeratotic and hyperpigmented on the dorsa of her hands. No excoriations, denuded areas, petechiae, or purpura were noted. Examinations for Darier's and Nikolsky's signs were negative. There was no evidence of dermatographism. On abdominal examination, the patient was noted to have a palpable nontender liver edge approximately 4 to $5 \mathrm{~cm}$ below the right costal margin. Sclerae were anicteric, and no jaundice was noted. No splenomegaly was noted.

Laboratory evaluation included a complete blood count and assessments of serum electrolytes, blood urea nitrogen, creatinine, and glucose, the results of which were normal. Other tests that were performed and their results are as follows: erythrocyte sedimentation rate (ESR), $22 \mathrm{~mm} / \mathrm{h}$ $(0-13 \mathrm{~mm} / \mathrm{h})$; alanine transaminase, $301 \mathrm{U} / \mathrm{L}$ (30-65 U/L); aspartate transpeptidase (AST), $182 \mathrm{U} / \mathrm{L}(15-37 \mathrm{U} / \mathrm{L})$; and $\gamma$-glutamyltransferase, 444 U/L (5-55 U/L). Total protein, bilirubin, albumin, antinuclear antibody (ANA), C4, and the viral hepatitis panel were within normal limits. Abdominal ultrasonography revealed a mildly enlarged liver of normal echogenicity and without evidence of cholelithiasis.

During the hospital course, the patient received intravenous morphine sulfate and oral diphenhydramine (12.5 mg, as needed) for pain and itchiness. The edema, erythema, and pain of the hands and feet resolved within 48 hours, without any scarring.

The allergy service was consulted to assist in the evaluation of the cutaneous findings. The ini- tial differential diagnosis included acute allergic angioedema, hereditary or acquired angioedema from $\mathrm{C} 1$ inhibitor deficiency, idiopathic angioedema, contact dermatitis, viral or bacterial infection with skin manifestations, autoimmune inflammatory disorders, malignancy, and metabolic disorders (including cutaneous porphyrias). ${ }^{1}$

The work-up included immediate-hypersensitivity skin testing with indoor and outdoor aeroallergens to evaluate for an IgE-mediated trigger for the pruritic dermatitis. This was performed with the prick method, and the result was negative with a positive histamine control. With a normal C4 level during an acute episode, hereditary or acquired angioedema from $\mathrm{C} 1$ inhibitor deficiency was unlikely but was not fully ruled out. Autoimmune disorders were less likely because the ANA level was normal and the ESR was elevated only mildly, but an assessment of extractable nuclear antigens was not done. The normal complete blood count lessened the likelihood that the skin findings were from a viral or bacterial source or from a malignancy such as leukemia. As the erythema and edema were of acute onset and resolved within 48 hours, contact dermatitis was less likely to have been the cause. The liver transaminases were persistently elevated, and viral hepatitis testing results were negative, which prompted further testing for metabolic disorders, including urine and plasma porphyrin analysis and liver biopsy. The patient did have a significantly elevated protoporphyrin level in the plasma $(1,970 \mu \mathrm{g} / \mathrm{mL}[0.4-4.8 \mu \mathrm{g} / \mathrm{mL}])$, and examination of the liver biopsy specimen confirmed the diagnosis of EPP; there was an accumulation of dark brown pigment displaying pathognomonic Maltese-cross figures on birefringence, with associated nodular fibrosis. ${ }^{3}$ No genetic testing has been performed to date.

The patient was started on beta carotene, cholestyramine, ursodiol, vitamin E, and sunscreen (sun protective factor [SPF] 50). The patient has been on this treatment for the last 10 months, and her liver function has been stabilized; however, she has had intermittent episodes of erythema and itchiness of the skin on sun-exposed areas such as her face and extremities, even with sunscreen use. The pruritus has been partially alleviated with the administration of hydroxyzine. The patient's father, 
who is asymptomatic, was subsequently found to have elevated liver transaminases; however, he has refused further evaluation through liver biopsy.

\section{Discussion}

EPP is a rare disorder of heme biosynthesis characterized by early-childhood onset of acute photosensitivity of sun-exposed skin. ${ }^{4,5}$ It is an autosomal dominant disorder with incomplete penetrance. ${ }^{6}$ Its prevalence in the general population is 10 to 20 per 100,000 , without any ethnic or gender predominance. ${ }^{3} \mathrm{EPP}$ is caused by a deficiency of ferrochelatase, the final enzyme in heme synthesis, which leads to an accumulation of protoporphyrin in various tissues, including the skin and liver. ${ }^{5}$ The release of protoporphyrin from erythrocytes is increased if the erythrocytes are exposed to light. The cutaneous symptoms are a consequence of protoporphyrinsensitized photodamage of endothelial cells as well as initiating inflammatory pathways. Free oxygen radicals are released from the lightexcited protoporphyrins, which leads to peroxidation of lipids and cross-linking of membrane proteins, which causes hemolysis of erythrocytes. ${ }^{2}$ Protoporphyrin also induces the release of mast-cell mediators such as histamine, prostaglandin D, leukotrienes, and plateletactivating factor. ${ }^{1}$ Complement activation with the generation of anaphylatoxins also plays a role in the phototoxicity. ${ }^{2}$ Polymorphonuclear cell chemotaxis also increases to the affected area after light exposure. ${ }^{2}$

Typically, EPP presents in childhood; the affected child cries and complains of burning of the skin on the face and hands within minutes of sun exposure. Delayed effects that occur several hours later include swelling or erythema of the affected area. ${ }^{6}$ Petechiae and purpura may also occur; however, blisters or vesicles are uncommon. Patients may eventually develop a waxy cobblestone-like induration of the affected area, frequently on the knuckles and fingers. ${ }^{2}$ Major presenting symptoms and signs include burning (97\%), edema (94\%), itching (88\%), erythema (69\%), and scarring of the skin $(19 \%){ }^{7}$
Patients with EPP can develop liver disease ranging from stable liver transaminase elevation to acute hepatic failure requiring liver transplantation. Less than $10 \%$ of patients with EPP will develop severe liver disease. ${ }^{3}$ Hyperpigmented cholelithiasis from hemolysis also may present in young children. ${ }^{3}$ Mild anemia is also a common finding.

Diagnosis of EPP is based on elevated plasma, erythrocyte, or fecal concentrations of protoporphyrins with normal urinary porphyrins due to poor water solubility. ${ }^{8} \mathrm{~A}$ liver biopsy specimen may reveal an accumulation of deposits with periportal fibrosis. ${ }^{5}$ Molecular analysis of the ferrochelatase mutation reveals missense, deletion, and nonsense mutations, leading to functional deficiency of ferrochelatase. ${ }^{8}$ The gene has been mapped to chromosome $18 \mathrm{q} 22 .^{2}$

Treatment includes avoidance of sunlight and the use of topical sunscreen agents with an SPF of $>30$ and ideally containing reflective components such as zinc or titanium oxide. ${ }^{3}$ Oral administration of beta carotene has been used as well, at a dose of 120 to $180 \mathrm{mg}$ daily to achieve a serum beta carotene level of 600 to $800 \mu \mathrm{g} / \mathrm{dL} .^{8}$ Beneficial effects are usually seen 1 to 3 months after the initiation of therapy. ${ }^{8}$ The mechanism of action may be from the reducing of activated free oxygen radicals. ${ }^{2}$ Cholestyramine ( $5 \mathrm{~g}$, three times daily) has also been used to decrease porphyrin levels. ${ }^{5}$ Vitamin E and pyridoxine have also been used, with limited success. ${ }^{3,5}$ Transfusions of red blood cells and intravenous heme have been helpful in refractory cases ${ }^{3,5}$ At this time, ferrochelatase replacement is unavailable. ${ }^{2}$ The prognosis in general is good for most patients with EPP in the absence of liver failure. ${ }^{3}$

\section{Conclusion}

Although erythropoietic protoporphyria is rare disorder, it may initially present in patients in the pediatric age group. It may be important for allergists to recognize this entity at an early stage, especially in patients with cutaneous disorders of unclear etiology, to prevent possible lifethreatening complications. 


\section{References}

1. Kaplan AP. Urticaria and angioedema. In: Adkinson NF, Yunginger JW, Busse WW, et al, editors. Middleton's allergy principles \& practice. 6th ed. Philadelphia: Mosby, Inc.; 2003. p. 1537-47.

2. Lim HW. Pathogenesis of photosensitivity in the cutaneous porphyrias. J Invest Dermatol 2005;124:xvi-xvii.

3. Chemmanur AT, Bonkovsky HL. Hepatic porphyrias: diagnosis and management. Clin Liver Dis 2004;8:807-38.

4. Magnus IA, Jarrett A, Prankerd TAJ, Rimington C. Erythropoietic protoporphyria. A new por- phyria syndrome with solar urticaria due to protoporphyrinaemia. Lancet 1961;2:448-51.

5. Porphyrias. In: Habif TP, editor. Clinical dermatology. 4th ed. Philadelphia: Mosby, Inc.; 2004. p. 680 .

6. Dombeck TA, Satonik RC. The porphyrias. Emerg Med Clin North Am 2005;23:885-99.

7. DeLeo VA, Poh-Fitzpatrick M, Matthews-Roth M, Harber LC. Erythropoietic protoporphyria. 10 years experience. Am J Med 1976;60:8-22.

8. Sassa S. The porphyrias. In: Behrman RE, Kliegman RM, Jenson HB, editors. Nelson's textbook of pediatrics. 17th ed. Philadelphia: Elsevier; 2004. p. 495-504. 